\title{
Statistical Thinking Training Requirements and Strategy based on Interdisciplinary
}

\author{
Zhanzhen ZHANG \\ Qingdao University of Science \& Technology, College of economics and management
}

\begin{abstract}
Statistical thinking is thinking mode that people descriptive, analyze, judge and reason the quantity characteristic and law of objective things by data consciously, it has the characteristics of quantity, fault tolerance and variability. Cultivating statistical thinking needs to pay attention to develop and improve students' thinking of divergent, novelty and uniqueness, pay attention to the combination of theory with practice, emphasizes the combination of qualitative analysis and quantitative analysis, and combine with different disciplines background. According to these requirements, statistical teaching should focus on the exchange of teaching and learning to expand students' knowledge and thinking space, improve students' practical applicative ability through the theory with practice; improve the students' ability of data processing by multimedia and statistical software.
\end{abstract}

KEYWORD: Statistical thinking; Training requirements; Teaching strategies

\section{GENERAL INSTRU5CTIONS}

With the development of social economy and the progress of science and technology, we contact with all kinds of data every moment, we will not be able to survive without statistics. Where the data come from, what's the relationship between implicit and law? What theory and method should we use to sort and analyze these data, and what kind of conclusion can we come to? Answers to these questions rely on statistics. Therefore, learning statistical theory and method, cultivating statistical way of thinking have become the basic requirement of economic management specialty students. It can make you have the ability of designing, collecting, sorting and analysis of statistical data.

Famous scholar H.G.Wells once said statistical thinking would become a productive citizen's necessary ability just like reading and writing someday. There is no doubt that cultivating statistical thinking has become a required element of the higher education personnel training. The view is not only embodied in making students master the basic knowledge of statistics, but also making students form the habit of statistical thinking and have the ability to use statistical methods to solve practical problems.

For example, in the analysis of specific issues, you should try out an idea in statistical thinking; in dealing with the problem, you can accurate positioning from the overall view, number and differences; in decision analysis, you should calmly analyze and grasp of things uncertainty, risk control to a minimum. However, all of the abilities are not instinct. They need to get through continuous learning and practice. For students of economic management, you should study the professional knowledge systematically, at the same time, also must study statistical knowledge systematically. For this reason, the ministry of education clearly stipulates that statistics is one of the core courses in higher school finance majors.

\section{DEFINITION OF THE CONCEPT OF STATISTICAL THINKING}

\subsection{Concept of statistical thinking}

Junfeng YIN, Wuyi ZENG (2001) thought statistical thinking includes three different elements: process thinking, fluctuating and figures, they contacted each other. Cultivating good statistical thinking could promote the effective application of other thinking ways. it was a basic thought runs through the whole process of teaching statistics. [1] Wenzhang HUANG (2009) thought probability and error were the two pillars of statistical thinking. [2] Qina HUI (2010) thought statistical thinking was a thinking method that people descriptive, analyze, judge and reason the characteristics and the law of objective 
things with quantity consciously, it had the characteristics of quantity, fault tolerance, reverse thinking. [3] Shuang WANG, Xiang WU (2012) argued statistical thinking was a kind of uncertainty thinking, it was a thinking mode that reflected in the process of extracting data, extracting information from data, the conclusion of reliability, etc. [4] Jianjun ZHOU, Li ZHANG, Niansheng TANG (2013) showed that the statistical thinking should think in statistical view when facing various problems in the social life, analyze and solve problems with the proper use of mathematical statistics. [5]

\subsection{Cultivating of statistical thinking}

Xizhi WU (2003) thought reverse thinking should be cultivated in statistical teaching and research, reverse thinking can be innovative. [6] Yuhong LI, Xia WANG, Jin ZHANG (2009) analyzed the concept of statistical thinking and the statistical thinking in statistics, they thought cultivating statistical thinking was an effective quality education, strengthen the statistical thinking need to carry out teaching reform in teaching method of statistics. [7] Yuanguo YAO (2008) thought cultivating students' random thinking and ability of solving practical problems was the main teaching tasks of "probability theory and mathematical statistics".[8]Shuang WANG, Xiang WU (2012) considered the training statistical thinking need to realize by innovating education idea, reforming the teaching content, changing the teaching mode and in teaching process. [4] Jianjun ZHOU, Li ZHANG, Niansheng TANG (2013) thought the basic idea of training statistical thinking was a teaching mode of taking the course as the master line, taking the teacher as the leadership, taking the students as the center, theory teaching and practice teaching permeate into each other's " . [5]

In summary, this paper considers statistical thinking is a thinking mode to grasp the quantity feature and the law by doing description, analysis, judgment and reasoning, it has the quantity, fault tolerance and reverse characteristics, it is a kind of uncertainty thinking mode. The fundamental statistical thinking is the idea of probability, we should analyze the results with probability theory, although we still use mathematical means of deterministic phenomenon of abstraction, computation, reasoning in the process of learning statistics, the statistical conclusions is not absolute.

\section{REQUIREMENTS OF STATISTICAL THINKING IN CULTIVATING IN STATISTICS TEACHING}

\subsection{Paying attention to students' thinking of divergent, novelty and uniqueness}

The purpose of statistical research is to explore the populations' numerical characteristics by collecting and studying data. But the main of teaching in traditional statistical confined to the interpretation of statistical basic knowledge and model formula derivation, the teaching pattern is similar to the mathematical study of abstract numbers, the students are used to seek the only correct answer, their scope of knowledge are narrow, study abilities are relatively poor. Therefore, from the perspective of statistics teaching reform we must strengthen the "parasitic" of statistics, expand student of knowledge, increase the teaching of related subjects, increase the related case analysis, focus on cultivating students' thinking of divergent, novelty and uniqueness, strengthen training of application ability of students.

\subsection{Paying attention to the combining of theory and practice}

Statistical research object is quantity, mass, specific characteristics, variability. Statistical researchers must collect data by going into matters deeply, and you can come to a conclusion combined with the specific problems through a large number of induction and deduction. For example, when investing in stocks, we should not only understand the share price, price earnings ratio and technical analysis indicators, but also understand the general situation of listed companies, relevant financial information, shareholders, equity structure, risk factors based on company's information research. And you can make the correct judgment and decision-making by establishing appropriate model, you should explore the changing law, combined with the macroscopic change in the stock market based on the related data collation and analysis.

\subsection{Emphasizing on quantitative analysis and qualitative analysis}

Statistical research not only focus on the quantitative characteristics of objective phenomena, but also emphasizes the qualitative understanding of phenomena, in the teaching process the statistical concept of combining of qualitative analysis and quantitative analysis should be concerned.

For example, we would research how to improve residents' consumptive abilities. Firstly, we need to seek the theoretical foundation in economics, explore the relationship between consumption and income, family structure, the consumption 
environment, consumer expectation, consumer confidence and other factors; Secondly, we should study the relationship between consumer spending and the influencing factors through statistical indicators and statistical graphics; thirdly, we should establish the corresponding statistical model to predict the future consumption ability according to the change trend of each factor, put forward the measures and the specific path to enhance the residents' consumption ability based on the statistical significance test.

\subsection{Combining with the professional application background}

Statistics is a unique knowledge which is the study of the data from various fields, there is no fixed object of study, its existence and prosperity is by solving related problems in other field. An America statistician, Leonard Jimmie Savage said statistics was basically parasitic on other fields of study, this is not to show contempt, on the contrary it precisely reflects the importance of statistics. Renowned economist in China, Yinchu MA once said a very incisive word: "scholars can't research without statistics; politicians can't make policy without statistics; entrepreneurs can't practice without statistics." Some scholars said other science can exist without statistics, but they would be very small." So for economic management majors, the objective of learning statistics is to make students acquire a correct understanding of theory and method about law of quantity of social economic phenomenon, and to solve specific problems in the management and economy aspect. Therefore, the teaching of statistics needs to combine statistical knowledge with students' professional and application background, the teachers need to pay attention to hot problem of the social and economic life, analyze these problems by statistical methods.

\section{TEACHING STRATEGY OF CULTIVATING STATISTICAL THINKING}

\subsection{Paying attention to the communication of teacher and students, and expanding students knowledge and thinking space}

Statistical thinking is a mode of thinking that people consciously use data doing description, analysis, judgment and reason on the quantity characteristics of objective things. it is a kind of uncertainty of the concept. Statistical conclusions are usually not unique. In the process of teaching, the professors must pay attention to the communication of teacher and students. Teachers should guide students to think and express a unique insight from different perspectives; some discussions are used in class to promote the exchange of information and communication so as to broaden the students' thinking space. In addition, statistics is a discipline basic course in college of economic and management, teaching should also take into account the whole knowledge link, so it is necessary to pay attention to the combination of mathematics, computer and other related professional courses. The professors should optimize the repeated courses through discussion, coordination and reasonable division of labor. Students would understand the cross and the transition between disciplines, master the knowledge learned, enhance the professional comprehensive ability.

\subsection{Improving students' practice abilities guided by practical application}

Statistics is an applied discipline. The purpose of statistics teaching is to cultivate the students' statistical skills and practical abilities. Statistics teaching should highlight the principle of "professional service, outstanding application", and consider the cultivation of practical application ability as the guidance, design reasonable teaching content, optimize teaching methods, pay attention to cultivate the students' digital sensitivity, improve their statistical literacy. It has been widely recognized that case teaching and practice teaching in the statistics teaching can improve students' statistical skills. Case teaching is the real simulation in practice, the practice conditions and environment can be built, the best case of collecting is the choice of statistical application in related field. The statistical case should briefly describe the background and the statistical methods. Real case can help students to connect the phenomenon of knowledge and economy visually. Firstly, the teacher should give relevant materials to students; Secondly, students form groups to think, discuss and analysis, each group sent representatives to explain the process and results of analysis in a fixed period of time, other members can be added; Finally, teachers make comprehensive evaluation according to the report and the participation of group members.

Combining with professional practice of each specialty, teachers can arrange a statistical practice. Students would experience the process of analyzing problems, understand the problem and solve problems by using the statistical method, laying the groundwork for the study of professional knowledge and also laying a solid foundation for later work practice in proper use statistical method.

\subsection{Improving the students' ability of data processing by multimedia teaching and statistical software}

The introduction of multimedia teaching can make 
the abstract concept, formula, dull figures vivid and intuitive, statistical software can simplify data processing, operation process, demonstrate a variety of charts to students. By this method, the teaching process can combine the statistical application closely. Teaching emphasis turn to analysis the results instead of calculating, it can improve the application abilities of the students rapidly. Multimedia teaching means are used in class. It communicates teaching content by text, graph, color, sound, animation and other forms. It not only can create a lively atmosphere in the classroom, but also improve the initiative, the enthusiasm of the students. However, in the practice of teaching, multimedia is used to take into account its rationality, courseware is not too fancy, also not too rigid, teachers should reasonably refine, arrange lectures according to the specific teaching content and the actual situation of students, do highlight, prioritize, and strengthen exchanges and interaction with students to achieve better teaching effect.

The use of statistical software is one of the required content of modern statistical teaching, such as Excel, SAS, SPSS, Minitab, etc. They play respective advantage in different fields, they improve the quality of the statistical work and efficiency. To students of non-statistics majors, mastering the Excel and SPSS statistical software is the most basic requirements, some students can also focus on other software. The teachers should explain statistical points by using the specific case, the students could learn how to create tables, charts, models with Excel and SPSS. They could also carry on the preliminary statistical research and analysis by using statistical thinking mode.

In summary, teachers should be innovative ideas of teaching and optimize the teaching methods, teaching means, teaching art combined with the professional background of students. We can achieve good teaching results in the statistics teaching in college of economy and management.

\section{REFERENCE}

[1] Wenzhang HUANG. 2009. Statistical thinking. The Mathematical Communication Quarterly, 33(4):30-46

[2] Junfeng, YIN. Wuyi, ZENG. 2001 Statistical teaching should focus on the development of the students' statistical thinking. Statistical education, 1: 6-7

[3] Qina HUI. 2010. Look at the statistics teaching reform from the statistical thinking ability. Statistics and decision making, 3:168-170

[4] Shuang WANG, Xiang WU. 2012. Discussion on teaching reform about training statistical thinking. Journal of Northeast Dianli University, 10:53-55

[5] Jianjun ZHOU, Li ZHANG, Niansheng TANG. 2013. Thinking of training statistical thinking in the teaching of statistics. Science and technology information, 23: 19, 29

[6] Xizhi WU. 2003. Reverse thinking and statistics. Statistics and information forum. 1:5-7

[7] YuHong LI, Xia WANG, Jin ZHANG. 2009. The development of College Students' statistical thinking under the background of quality education. China Adult Education. 20:95-96

[8] Yuanguo YAO.2008. Cultivation of random thinking ability in the teaching of probability and statistics. Education and occupation, the theoretical version, 2:112113 